\title{
Subsidy Risk Related to Construction Projects: Seeking Causes
}

https://doi.org/10.1515/eng-2018-0060

Received April 16, 2018; accepted July 18, 2018

\begin{abstract}
Many construction projects are realized with public subsidy, e.g. subsidies from the European Union, state budget and/or municipal resources. The reimbursement of the subsidy depends on a number of conditions, such as completion of the project in time or compliance with operation conditions. The purpose of this research is to seek causes of subsidy risk related to construction projects. In particular, research aims at addressing causes that may lead to the loss of subsidy, reduction of subsidy and/or a penalty payment. Research is conducted as a case study of selected construction projects and the Czech Republic is chosen as a study area. Set of data representing 20 construction projects which faced the threat of reduction or loss of subsidy was collected from available sources and results represent the spectrum of identified risk causes and their distribution in the different phases of the project life cycle and according to the risk source breakdown structure. From managerial perspective, output of this research may serve as a support for investors who plan to apply for public subsidy for their construction projects. Several recommendations for subsidy risk avoidance have been proposed at the end of the paper.
\end{abstract}

Keywords: Construction project, procurement, project life cycle, risk source, subsidy risk

\section{Introduction}

Public construction projects have an important share on the creation of potential GDP of the Czech Republic and thus contribute to the future economic growth of the country. They are very important for the development of individual regions, especially for their multiplier effect reflected in the supplier sector or employment rate. With

\footnotetext{
*Corresponding Author: Tomas Hanak: Brno University of Technology Brno, Czech Republic, E-mail: hanak.t@fce.vutbr.cz Jana Korytarova: Brno University of Technology, Faculty of Civil Engineering, Brno, Czech Republic
}

regards to the fact that these projects are funded from public sources, both national and international (in particular EU funds), their implementation requires high demands on their management, especially from the processadministrative point of view as well as from the point of view of the construction project management. This means not only monitoring the costs and timetables, but also conditions of their financing from subsidy sources. Risks that can arise from the fact that all the conditions for the final application for the subsidy have not been met are defined by authors as a subsidy risk.

The aim of the paper is to investigate which risk causes arise from the financing of construction projects from public subsidy sources and whether certain risk sources can be considered as dominant - those which repeat with a higher frequency than the others. Another related output of the research are the findings concerning in which phases of the project life cycle the risk causes occur.

\section{Background}

There is inexhaustible number of risks definitions and their division, often related to the specific issue dealt with. The risk associated with construction projects is for the research findings of this article defined as the level of possible deviation of actual results from the expected results, when the risk impact can be measured as the likelihood of a specific unwanted event and its unwanted consequences or loss [1]. Mills [1] also states that risk management improves the changes of the project being completed on time, within budget and to the required quality. A systematic and coordinated way of working with risk and uncertainty should be applied within the entire project life cycle. The risk management process can be divided into the following stages: (1) identification; (2) analysis, and (4) response [2]. There are more approaches to risk management; therefore it is important to consider choosing an appropriate risk management methodology with respect to the nature of the project [3] as risk indicators are dependent on the type of project and its environment [4]. 
The authors of this article focused in their research on one of the areas of risk management, the process of identifying the risks in a public construction project. The risk affects all aspects of the project, including costs, quality and time. Impact of the risk may be mitigated or even fully eliminated if the risk sources are timely identified and then managed appropriately. For work with risk, the classification of risks according to the factual content is usually used in construction practice. The standard view is the division of risk sources in external (acting on the project from outside) and internal (occurring within the project). Dunovic et al. [5] include legal, political, economic, social and natural sources in external risk sources and management, technical and human factors, procurement and contractual sources in the internal risk sources. These risks may occur throughout the entire construction project life cycle. The life cycle of a construction project represents a very long period, starting with the formulation of the investment plan, the subsequent realization of the construction work, the operation of the construction work and the completion of the construction project by its liquidation. The lifecycle of a construction project can be divided into four consecutive phases (pre-investment, investment, operational and liquidation), which can be further divided down to the level of partial phases that carry specific activities and documentation of the construction project condition. In the pre-investment phase, one of the key documents for decision-making process whether it is meaningful to realize the project, is so called feasibility study, which should include, among other things, identification of potential project risks and it should be known how will the project manager deal with the risks if they occur. One of the more risky periods in the lifecycle of a public construction project is its investment phase, which can be further divided, for example, according to [6] into planning and realization (rough phases) which involve partial phases and their main activities.

The authors of this article also focused on the specific risks of construction projects funded by national or international (especially EU) public resources. For the projects co-financed by the EU Structural Funds and/or the EU Cohesion Fund, the eligibility rules for expenditures also apply. These are the costs that can be financed from these subsidies. Eligible expenditures are expenditures that are in compliance with the corresponding EU and national regulations (e.g. CR), they correspond to the objectives, focus and areas of support of the subsidy provider, they are indispensable for realization and achievement of the project objectives, comply with the rules of the provider and fulfil the principles of $3 \mathrm{E}$ (Economy, Effectiveness, Efficiency). The eligibility of expenditure is affected by the time perspective (start, end of the project and the moment of expenditure occurrence), the material nature of the expenditure (investment, non-investment expenditure), proof of expenditure eligibility (requirements of the accounting and reimbursement documents) and compliance with the rules of the subsidy provider (e.g. procurement guidelines, change management and bookkeeping).

Available scientific literature provides some insight into subsidy issues related to construction projects. For example model assessing relationship between project viability with project risk and government subsidy was developed in [7], relationship between the governmental financial subsidies and various influencing factors of public housing based on PPP model was addressed in [8] and financial support to construction and demolition waste recycling projects were mentioned in [9]. The results presented in this article broaden the current state of knowledge by the view of the subsidy as a risk influencing the construction project and its investor.

For the purpose of this study, as subsidy risk are considered such facts which implementation in the project result in proceedings for repayment or reduction of the subsidy, eventually a decision on imposing a fine by the subsidizing body. However, these proceedings are considered irrespective of their final outcome, i.e. whether or not the recipient of the subsidy has been forced to return a part or the whole subsidy or whether it has been or not has been fined imposed a fine for breaching of budgetary discipline. In order to eliminate the subsidy risk, it is therefore crucial e.g. to consider qualification requirements properly [10], to ensure technical specification in adequate detail [11] (in order to avoid the most frequent errors such as unclear and imprecise wording, incorrect layout of the specification or copying the records from other documents). It is therefore important to foresee the situation as realistically as possible [12]. However the low predictability of processes related e.g. to the renovation of historical buildings [13] might be really challenging in this relation.

The investor must be aware that construction contract is a complex agreement with high economic significance resulting from high amounts of investment [14]. As a result, errors in investment planning can bring investors into difficult situations, especially if additional financing such as subsidy from public funds needs to be secured [15].

\section{Materials and Methods}

In order to achieve research objective, the data on 20 construction projects has been collected from available 
sources. These sources include Information System on Public Contracts, web sites of the Regional Councils of relevant regions (such as South-East Cohesion Region or Moravia Silesia Region), European Structural and Investment Funds web site and relevant press releases. For each project, following structure of information, the following has been collected if available: (1) title of the project, (2) expected cost of the project, (3) amount of subsidy allocated, the result of the project regarding its (4) realization and (5) decision on subsidy. Post audit of these projects has been conducted and brainstorming and assumption analysis have been used as risk identification tools and techniques.

The aim of the research has not been collecting a large set of data regarding similar projects with identical and/or similar subsidy risk causes; instead the effort has been made to get information on projects of varying nature and with different subsidy issues. In particular, these projects include sport facilities, water/sewage systems, heritage building, animal keeping facility (ZOO), cultural facilities, transport infrastructure (roads, bicycle path), incineration plant and residential buildings. The diversity of projects is a good prerequisite for identifying both common and unusual risks arising in specific contexts of unique projects. As a result of available data analysis, the possible secondary impacts of subsidy risk occurrence have been discussed. The project cost fell within the range of CZK 9,600 - 200,000 thousand which represents app. EURO 380 7,900 thousand.

In order to reveal the position of risk causes within the project life cycle, they are assigned to the individual project phases according to [6] that are pre-investment, investment (with subdivision into planning and realization) and operation phases. The second dimension is to assign risks to the risk source structure proposed by Dunovic et al. [5]. For the purposes of the analysis, the subsidy authorities have been considered to be external stakeholders.

\section{Results and Discussion}

Comparison of expected costs of the project subsidy amount allocated indicates that the relative subsidy amount is often very high (the share of the subsidy on the expected value varies between $22 \%-96 \%$ in the examined set of data) and therefore the implementation of the project often depends on the availability of the subsidy. In this context, it should be noted that in the case of subsidy withdrawal, this may have major financial implications for the investor such as a small municipality. Table 1 provides basic information about analyzed projects (project subject and identified risk cause).

The data in Table 1 shows that projects often face the problem of meeting deadlines. These problems are related to the appeal of tenderers to the works contractor (P1, P2) which, if forwarded to the OFPC or the court (P2), extends to such an extent that it is not technically possible to do all the work in the remaining time and finish the work properly. In these cases, it is often decided not to implement the project. The project can also reach the deadline crisis during the project own implementation when the work is not fast enough due to weather, organizational or other reasons. In order to complete the project in time, it may happen that some work is not done according to the prescribed technological procedures, and thus defects will start to appear in the near future (see P4). Other identified causes include changes to the project without discussion and approval by the subsidy authority (P6a, P19, and P20), delays in preparation for construction or execution of the work itself ( $\mathrm{P} 7, \mathrm{P} 10)$ or legal issues (P8, $\mathrm{P} 11)$. The most frequent problem was tender errors (P9a, P12, P13, P15, and P16b).

When categorizing individual risk causes from the point of view of the project life cycle and its nature, Figure 1 clearly shows where they occur most frequently. When comparing internal/external risk sources, the analysis carried out clearly shows that risk causes are predominantly of internal character, with managerial (P7, P10, P17), technical (P4, P9b, P14, P19, P20), procurement (P1 , P2, P6b, $\mathrm{P} 9 \mathrm{a}, \mathrm{P} 12, \mathrm{P} 13, \mathrm{P} 15, \mathrm{P} 16 \mathrm{~b})$ and contractual $(\mathrm{P} 3, \mathrm{P} 5)$ risk sources. In the case of external risk sources, only the legal sources (P6a, P8, P11, P16a, P18a, and P18b) related to permits, approvals, standards, changes in law or local regulations are listed.

From the point of view of the project life cycle, the risk causes have been found in all phases except for the liquidation phase, since none of the researched projects is currently at this stage. Most risk factors have been found in preparation of realization (in Figure 1 marked as Rpreparation, $\mathrm{P} 1, \mathrm{P} 2, \mathrm{P} 6 \mathrm{~b}, \mathrm{P} 7, \mathrm{P} 12, \mathrm{P} 13, \mathrm{P} 14, \mathrm{P} 15$, and $\mathrm{P} 16 \mathrm{~b})$. In six and seven cases, risk causes have appeared in the execution phase (in Figure 1 marked as R-execution) and in the planning phase respectively. An interesting finding is the fact that the risk causes found in the pre-investment and operational phases are related exclusively to the legal aspects for the researched sample.

The performed analysis has also shown that the most critical point from the perspective of subsidy risk causes is the procurement issues during the preparation of project realization. Therefore, due attention should be paid especially to the quality of tender documentation [11], use 
Table 1: Overview of projects and identified risk causes

\begin{tabular}{|c|c|c|}
\hline Project ID & Subject of the project & Subsidy risk cause \\
\hline P1 & Sport facility & $\begin{array}{l}\text { Delay - appeal of some participants against the tender } \\
\text { procedure }\end{array}$ \\
\hline \multirow{3}{*}{$\mathrm{P} 2$} & & Delay - appeal of some participants against the tender \\
\hline & Sewerage system & procedure, appeal to OFPC (Office for the Protection of \\
\hline & & Competition), Regional court \\
\hline \multirow[b]{2}{*}{ P3 } & & Delay in handing over the property when the municipality \\
\hline & sewerage system & leaves the union of municipalities \\
\hline \multirow{3}{*}{ P4 } & Heritage huilding & Hurrying up the construction work due to the short \\
\hline & merlage Dullams & implementation time \\
\hline & & Failure to provide detailed information on the extent to which \\
\hline P5 & Animal keeping facility & $\begin{array}{l}\text { the contractor has carried out extra work because of the } \\
\text { protection of know-how }\end{array}$ \\
\hline \multirow{2}{*}{ P6 } & Cultural facility & (a) Change of the project without approval by the subsidy \\
\hline & Cutcurat ractity & authority, (b) Taking into account the rating of the banks \\
\hline \multirow{2}{*}{ P7 } & Transnort infrastructure & Request for extension of the construction period by the \\
\hline & Tramsport mirastructure & contractor due to delay in the preparation of the construction \\
\hline P8 & Incineration plant & Unauthorized waste management plan \\
\hline P9 & Animal keeping facility & $\begin{array}{l}\text { (a) Mistakes in the selection procedure (non-quorate selection } \\
\text { committee), (b) Increase in the project costs on the things not } \\
\text { covered by the project documentation }\end{array}$ \\
\hline P10 & Museum & Delay in construction \\
\hline P11 & Transport infrastructure & Cancellation of the building permit \\
\hline P12 & Sewerage system & Non-transparent determination of the winner by electronic raffle \\
\hline P13 & Sport facility & Discriminatory terms of the selection procedure \\
\hline \multirow{2}{*}{ P14 } & Sewerage system & A part of the sewerage system already completed has been \\
\hline & sewerdge system & placed within the scope of the project \\
\hline P15 & Transport infrastructure & Non-compliance with the tender conditions of the investor \\
\hline \multirow[b]{2}{*}{ P16 } & & (a) Non-observance of the amount charged for sewer rates to \\
\hline & Sewerage system & $\begin{array}{l}\text { the citizens determined by the financial analysis of the project, } \\
\text { (b) Reduction of the guarantee in the contract for work, while } \\
\text { the guarantee was an evaluation criterion }\end{array}$ \\
\hline \multirow[t]{2}{*}{ P17 } & Residential building & Delay of the project during approving project documentation \\
\hline & & (a) Means of future owners of apartments were used in violation \\
\hline P18 & Residential building & $\begin{array}{l}\text { of the conditions for the construction, (b) Allocation of } \\
\text { apartments in violation of the conditions of the subsidy }\end{array}$ \\
\hline P19 & Heritage building & Large number of project changes without reconciliation \\
\hline P20 & Sport facility & $\begin{array}{l}\text { Construction of a diving tower in a different way than according } \\
\text { to the project documentation }\end{array}$ \\
\hline
\end{tabular}

of non-discriminatory qualification requirements [16] and application of appropriate evaluation criteria.

The analysis of the research sample has also identified secondary impact of the subsidy risk on the project or on the investor as such. An example may be the final decision of the investor not to implement the project due to the fear of the subsidy loss in case of delay in preparation of the construction project and thus postponing its implementation for the future period. As example may serve an unrealized repair of a water or sewerage network which has had a secondary effect on subsequent scheduled repairs of the communication.

\section{Conclusions}

The core of the research described in the article is focused on the initial phase of the risk management of construction projects which is risk causes identification. In a research sample of 20 projects, 24 risk causes which caused subsidy risk have been identified. Based on the similar- 

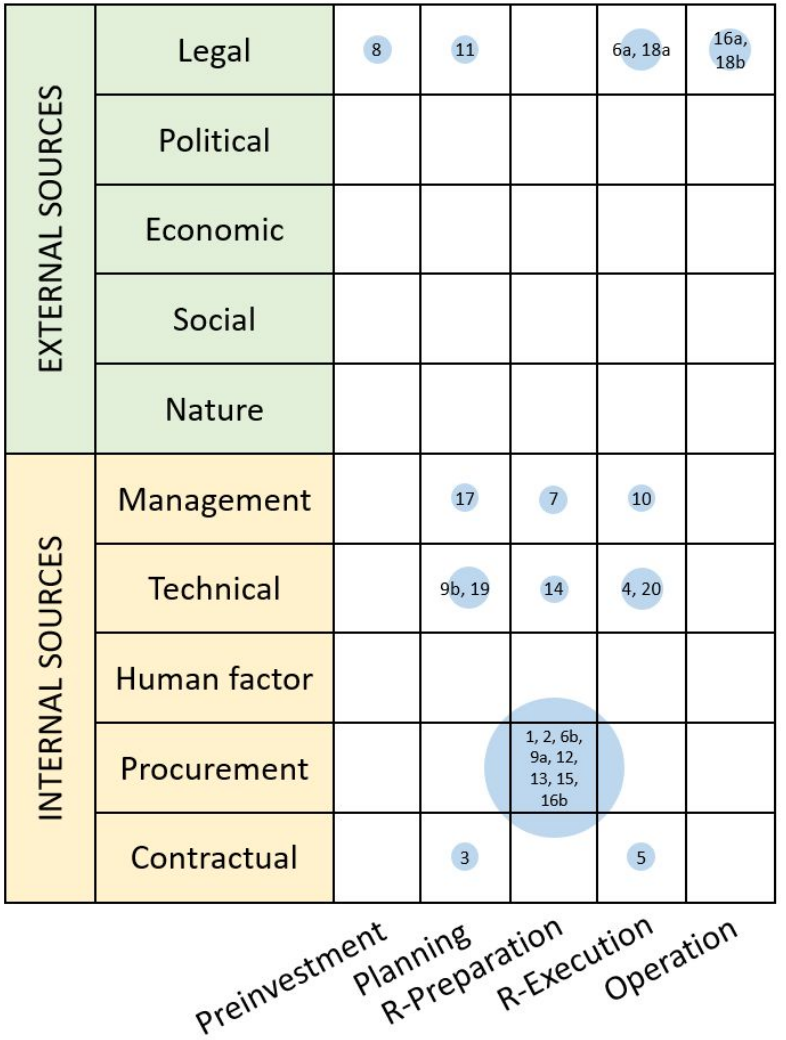

Figure 1: Two-dimensional risk cause breakdown structure

ity and/or differences in the individual risk causes, these were classified as internal and/or external risk sources as described above. The highest risk identified was the procurement risk (33.3\%) which belongs to the internal risk category. The second most frequently represented risk was the legal risk (25.0\%), which belongs to the external risk category and subsequently the technical risk (20.8\%), one of the internal risks. While procurement risk appeared only at the beginning of the implementation phase, Rpreparation, technical and legal risks occurred during the whole life cycle. It is obvious that they can occur in the process of the project at any time. Data analysis has shown that procurement risk is significant in these projects, therefore timely and quality preparation of tender documentation, well-chosen qualification criteria, ongoing control of all administrative procedures and deadlines are, with the view of reducing the subsidy risk, essential for public construction projects.

Main research limitations are related to the limited set of data. Based on the fact, that the sample contains only 20 projects, the application of statistical tools was not appropriate. Extending the sample by other projects will allow for monitoring and evaluating the frequency risk causes in more sophisticated way. Secondly, in order to reveal details about related impacts of subsidy risk occurrence, additional data about analyzed projects needs to be provided.

Future research directions related to the investigation of subsidy risk related to construction projects should allow looking for possible connections between the character of risk cause and its consequential impact on the project. Furthermore, extended set of data should also enable to perform enhanced quantitative analysis and to propose appropriate risk mitigation measures.

Acknowledgement: This paper has been worked out under the project no. LO1408 "AdMaS UP - Advanced Materials, Structures and Technologies", supported by Ministry of Education, Youth and Sports under the "National Sustainability Programme I".

\section{References}

[1] Mills A., A systematic approach to risk management for construction, Structural Survey, 2001, 19 (5), 245-252.

[2] Perry J.G., Hayes R.W., Risk and its management in construction projects, Proceedings of the Institution of Civil Engineers (London), 1985, 78 (pt 1), 499-521.

[3] Kaczorek K., Krzemiński M. Ibadov, N., The problem of choosing risk management methodology at the example of railway construction, MATEC Web of Conferences, 2017, 117, 8 p.

[4] Skorupka D., Identification and initial risk assessment of construction projects in Poland, Journal of Management in Engineering, 2008, 24 (3), 120-127.

[5] Dunović I.B., Radujković M., Vukomanović M., Risk register development and implementation for construction projects, Gradjevinar, 2013, 65 (1), 23-35.

[6] Nový M., Nováková J., Waldhans M., Project management in building industry management, Acta Universitatis Agriculturae et Silviculturae Mendelianae Brunensis, 2012, 60 (7), 189-198.

[7] Liou F., Huang C., Chen, B., Modeling government subsidies and project risk for financially non-viable build-operate-transfer (BOT) projects, EMJ - Engineering Management Journal, 2012, 24 (1), 58-64.

[8] He Y., Li B., Government financial subsidies in the influence of public housing under the PPP financing model, Proceedings of the 17th International Symposium on Advancement of Construction Management and Real Estate, 2014, 1123-1132.

[9] Huang B., Wang X., Kua H., Geng Y., Bleischwitz R., Ren J., Construction and demolition waste management in China through the $3 R$ principle, Resources, Conservation and Recycling, 2018, 129, 36-44.

[10] Plebankiewicz E., Construction contractor prequalification from Polish clients' perspective, Journal of Civil Engineering and Management, 2010, 16 (1), 57-64.

[11] Juszczyk M., Kozik R., Lesniak A., Plebankiewicz E., Zima K., Errors in the preparation of design documentation in public procurement in Poland, Procedia Engineering, 2014, 85, 283-292. 
[12] Car-Pušić D., Marović I., Gudac I., Comparison of budget and PPP model in financing public structures in post-transition environment, People, Buildings and Environment 2014, an international scientific conference, 2014, 3, 90-99.

[13] Radziszewska-Zielina E., Śladowski G., Proposal of the use of a fuzzy stochastic network for the preliminary evaluation of the feasibility of the process of the adaptation of a historical building to a particular form of use, IOP Conference Series: Materials Science and Engineering, 2017, 245 (7), 11 p.
[14] Marović I., Bošković D., Gudac I., Process approach in modelling Croatian construction contract management practice, International Journal for Engineering Modelling, 2012, 25 (1-4), 19-26.

[15] Dimitrov B., Žileska-Pančovska V., Structure of price elements for construction works on water engineering systems, Gradjevinar, 2015, 67 (4), 363-368.

[16] Korytárová J., Hanák T., Kozik R., Radziszewska-Zielina, E., Exploring the contractors' qualification process in public works contracts, Procedia Engineering, 2015, 123, 276-283. 